\title{
Contribuições da arquitetura da informação para o projeto de um repositório institucional
}

\author{
Bruno Pacheco Coelho Leite \\ Bibliotecário-Documentalista graduado pela UFES \\ Mestre em Biblioteconomia pelo PPGB/UNIRIO \\ E-mail: brunopcleite@gmail.com \\ Claudio José Silva Ribeiro \\ Professor Adjunto da PPGB/Unirio \\ Doutor em Ciência da Informação \\ E-mail: claudio.ribeiro@unirio.br
}

\begin{abstract}
RESUMO:
A partir do questionamento sobre como os elementos provenientes da Arquitetura da Informação podem contribuir no planejamento de um Repositório Institucional para o Instituto Federal do Espírito Santo, esta pesquisa teve como objetivo geral propor uma estrutura de organização da informação de um Repositório Institucional para o Instituto Federal do Espírito Santo. Seus objetivos específicos foram: analisar os aspectos teóricos e metodológicos que envolvem a Arquitetura da Informação para embasar a elaboração da estrutura informacional de um Repositório Institucional para o Ifes; coletar as informações institucionais do Ifes com o propósito de identificar e analisar as propriedades dos conteúdos presentes no âmbito organizacional; representar os componentes da estrutura informacional do repositório supracitado utilizando-se da modelagem conceitual. Quanto à sua metodologia, trata-se de uma pesquisa aplicada, qualitativa e exploratória, pois está voltada para a aplicação prática de soluções de problemas específicos por meio de análises conceituais que visam atender o objetivo proposto. Os resultados foram a criação de modelos de conteúdo e navegação para o ambiente informacional que é objeto deste estudo. A partir das análises dos modelos, concluiu-se que a Al pode fornecer um nível adequado para organização da informação dentro de um RI. Constata-se que o processo de modelagem auxilia no enriquecimento da representação dos conteúdos além de ser importante para que o arquiteto da informação identifique possíveis falhas no projeto.
\end{abstract}

Palavras-chave: Arquitetura da informação. Organização da informação. Repositórios digitais. Repositórios institucionais. Instituto Federal do Espírito Santo.

\section{ABSTRACT:}

From the questioning of how the elements from the information architecture can contribute to the planning of an Institutional Repository for the Instituto Federal do Espírito Santo, this research aimed to propose an information organization structure of an Institutional Repository for the Instituto Federal do Espírito Santo. Its specific objectives were to analyze the theoretical and methodological aspects involving the Information Architecture to support the development of the information structure of an Institutional Repository for Ifes; collect institutional information from Ifes in order to identify and analyze the properties of the contents in the organizational context; represent the components of the informational structure of the aforementioned repository using the conceptual modeling. As for its methodology, it is an applied research, qualitative and exploratory, it is focused on the practical application of specific problem solutions through conceptual analyzes that aim to meet the 
objective. The results were the creation of models of content and navigation to the information environment which is the subject of this study. From the analysis of the models, it is concluded that $\mathrm{Al}$ can provide an appropriate level for the organization of information within a RI. It is noted that the modeling process helps to enrich the content of representation as well as being important for the information architect identify possible flaws in the design.

Keywords: Information architecture. Information organization. Digital repositories. Institutional repositories. Federal Institute of the Espírito Santo.

\section{INTRODUÇÃO}

Diante do cenário de surgimento gradativo de ferramentas com mecanismos desenvolvidos para o armazenamento e disseminação do conhecimento registrado de forma permanente e acessível - do qual se beneficia a comunicação científica na atualidade, não se imagina o caminho de incertezas percorrido por diversos estudiosos em busca de tecnologias capazes de contribuir para o gerenciamento das informações provenientes de pesquisas realizadas no âmbito da comunidade acadêmica.

Vislumbra-se, por meio desta pesquisa, investigar os elementos e processos metodológicos advindos da Al, para a elaboração de uma estrutura informacional de um RI para o Instituto Federal do Espírito Santo (Ifes). Tal estudo faz-se necessário no atual contexto, onde as constantes mudanças econômicas, sociais e políticas ocorridas ao longo da história em conjunto com as tecnologias da informação e comunicação (TIC) ocasionaram um acentuado aumento na produção e disponibilização da informação científica.

Esta pesquisa pretende responder o seguinte questionamento: como os elementos provenientes da Arquitetura da Informação podem contribuir no planejamento de um Repositório Institucional para o Instituto Federal do Espírito Santo?

No que tange ao objetivo geral, o estudo busca propor uma estrutura de organização da informação de um Repositório Institucional para o Instituto Federal do Espírito Santo, com base nos elementos provenientes da Al.

Os objetivos específicos são: 1) Analisar os aspectos teóricos e metodológicos que envolvem a Arquitetura da Informação para embasar a elaboração da estrutura informacional de um Repositório Institucional para o Ifes; 2) 
Coletar as informações institucionais do Ifes com o propósito de identificar e analisar as propriedades dos conteúdos presentes no âmbito organizacional; e 3) Representar os componentes da estrutura informacional do repositório supracitado por meio da modelagem conceitual aplicada ao caso do Ifes.

Tendo em vista que o Ifes e a maioria dos outros IFs ainda caminham em busca de iniciativas voltadas para o gerenciamento das suas produções científicas, encontra-se nos Rls uma alternativa para impulsionar a divulgação e o acesso à informação científica.

\section{UM BREVE RELATO SOBRE OS REPOSITÓRIOS}

Para Costa e Leite (2009, p. 165), "a expressão repositórios digitais, no contexto do movimento mundial em favor do acesso aberto, é utilizada para denominar os vários tipos de provedores de dados que constituem vias alternativas de comunicação científica".

De acordo com Crow (2002), os repositórios digitais visam atender a dois assuntos estratégicos das Instituições de Ensino Superior e de Pesquisa: a) dispor de um ambiente que amplifique o acesso aos conteúdos de pesquisas, certificar o gerenciamento da produção acadêmica, diminuir custos e trazer visibilidade para a própria instituição e as bibliotecas; b) servir como indicadores tangíveis da qualidade da universidade e relevância das suas atividades científicas.

Entende-se que para a obtenção do desenvolvimento científico no Brasil, é imprescindível que os agentes responsáveis pela comunicação científica, incluindo as instituições acadêmicas, se comprometam a promover o acesso a suas pesquisas (IBICT, 2005). Dessa forma, um repositório institucional pode ser considerado um aliado na prestação desse serviço, pois se destina a "guardar, preservar e garantir livre acesso via internet, à produção científica no âmbito de uma dada instituição" (MARCONDES; SAYÃO, 2009, p. 9).

Barton e Waters (2004) declaram que um repositório institucional possui um conjunto de serviços voltados para a captura, armazenamento, indexação, preservação e redistribuição das pesquisas produzidas para toda a comunidade científica por meio dos materiais em formato digital.

Diante do exposto, acredita-se que os Rls se colocam como poderosos canais de difusão da produção intelectual e científica da instituição fomentadora do 
RI, evidenciando-se, também, como um importante recurso aberto a outros potenciais utilizadores, constituindo um patrimônio útil à sociedade em geral (ROSA; GOMES, 2010). Por todos esses aspectos, é possível considerar o RI como um elemento capaz de agregar valor para qualquer instituição de ensino e pesquisa.

\section{ARQUITETURA DA INFORMAÇÃO}

De acordo com Leite e outros (2012), para a construção de um repositório institucional são necessárias três etapas, tais como planejamento, implantação e funcionamento. Ressalta-se que a Arquitetura da Informação está presente na etapa de planejamento, conforme descrito por Leite e outros (2012), e tem como sua essência a "[...] organização da informação para ajudar efetivamente pessoas a satisfazerem suas necessidades de informação.

A Arquitetura da Informação é compreendida por quatro sistemas interdependentes, cada qual composto por regras e aplicações próprias. Juntos eles agrupam todos os elementos necessários para que o usuário interaja com o ambiente informacional digital. Morville e Rosenfeld (2006), divide a Al nos seguintes sistemas:

- $\quad$ Sistema de Organização - define o agrupamento e a categorização de todo o conteúdo informacional.

- Sistema de Navegação - especifica as maneiras de navegar; de se mover pelo espaço informacional.

- $\quad$ Sistema de Rotulação - estabelece as formas de representação e da apresentação da informação, definindo signos para cada elemento informativo.

- $\quad$ Sistema de Busca - determina as perguntas que o usuário pode fazer e o conjunto de respostas que irá obter.

Esta pesquisa adotou como pressuposto que o recorte necessário para elaborar o projeto de conteúdo contemplaria especialmente as sistemáticas de organização e navegação.

O Sistema de Organização é o componente da Arquitetura da Informação que possui o papel de definir as regras de classificação e ordenação das informações que serão apresentadas, aplicando-as na categorização de todo o conteúdo informacional oferecido. 
Conforme definido por D'Andréa (2006), os esquemas de organização são agrupamentos de informações com vistas a estreitar relações dos itens e conteúdos informacionais de acordo com as características dos mesmos. Como consequência, estabelecem-se categorias. Esses esquemas dividem-se em exatos, ambíguos e híbridos.

Segundo Monteiro (2008), os esquemas de organização exatos possuem maior facilidade de implementação, pois agrupam as informações por meio de características óbvias e mutuamente excludentes. Podem ser divididos nos seguintes tipos:

\begin{abstract}
Esquema de organização exato alfabético: é o mais intuitivo dos esquemas por apresentar as informações ordenadas alfabeticamente [...];

Esquema de organização exato cronológico: a ordem é definida a partir de um tipo de data, um recorte temporal [...];

Esquema de organização exato geográfico: o agrupamento de informações é realizado segundo aspectos espaciais [...] (MONTEIRO, 2008, p. 68).
\end{abstract}

No que diz respeito aos esquemas de organização ambíguos, afirma-se que eles são arbitrários, isto é, demandam esforço intelectual individual ou coletivo para a concepção de categorias e subcategorias representativas, que apoiem o agrupamento dos conteúdos informacionais com equivalência semântica (MONTEIRO, 2008). São distribuídos em:

\begin{abstract}
Esquema ambíguo tópico: compõe uma estrutura de conhecimento definida segundo o assunto das informações a serem disseminadas e, para tanto, o nível de especialização de seus usuários é uma observação relevante [...];

Esquema ambíguo orientado à tarefa: organiza conteúdos e aplicações segundo processos, funções ou ações. Estes esquemas são adequados quando é possível definir um conjunto limitado de tarefas que os usuários podem executar [...] como selecionar, recortar e colar [...];

Esquema ambíguo orientado ao público: define a criação de áreas específicas de navegação, ou sub-sites, de acordo com os tipos de usuário e seus respectivos interesses [...] que tem o propósito de facilitar a localização de informações comumente acessadas por estes grupos [...];

Esquema ambíguo orientado à metáfora: utiliza metáforas conhecidas pelo usuário para representar informações de maneira intuitiva, associativa. A metáfora procura aproveitar um conhecimento adquirido previamente para definir estruturas hipertextuais análogas, otimizando a navegação e ambientação do usuário [...] (MONTEIRO, 2008, p. 68-69).
\end{abstract}

Por fim, os esquemas de organização híbridos utilizam-se de elementos dos esquemas exatos e ambíguos.

Monteiro (2008) caracteriza as estruturas da seguinte maneira: 
Estrutura de organização hierárquica (abordagem top-down): hierarquias ou taxonomias são a base da organização. Subdivisões mutuamente excludentes e relacionamentos hierárquicos são comuns e utilizados há muito tempo na organização de informações. O modelo mental apresentado por este tipo de estrutura propicia conforto aos usuários, pois oferece uma organização familiar, sendo assim, excelente ponto de partida na arquitetura [...];

Estrutura de organização Base de Dados relacional (abordagem bottom-up): bases de dados são definidas como uma coleção de dados organizados para facilitar sua busca e recuperação. As informações são organizadas em registros, os registros possuem campos e estes campos contêm dados que descrevem um documento. Uma coleção de registros forma a base de dados $[\ldots]$;

Estrutura de organização hipertexto: agrupa conteúdos de acordo com um nível de semelhança ou critérios pré-definidos. O hipertexto é uma forma não linear de estruturar conteúdo em rede, na qual componentes são interligados por meios de links. Esses componentes podem ser textos, partes de textos, imagens, vídeos, etc. estabelecendo relacionamentos hierárquicos ou não [...] (MONTEIRO, 2008, p. 70-72).

Estes fatores de estruturação são imprescindíveis na customização de um repositório institucional, pois visa conceber uma interface de fácil compreensão e acesso, de modo a oferecer um adequado entrosamento entre o usuário que busca e o sistema que fornece a informação (TORINO, 2010).

Cabe ressaltar que o Sistema de Navegação é um componente da Al que se caracteriza pela sua coleção de recursos cujo objetivo principal é ajudar os usuários a encontrar informações e funcionalidades específicas, incentivando-os a tomar decisões desejáveis (CARDELLO, 2014).

O sistema de navegação embutida consiste em três esquemas (global, local e contextual) disponíveis dentro das páginas que indicam ao usuário onde ele está, onde ele esteve e aonde ele pode ir. Na Figura 1 é possível observar a localização de cada sistema, bem como suas questões fundamentais.

Figura 1 - Sistema de navegação embutida e as questões fundamentais
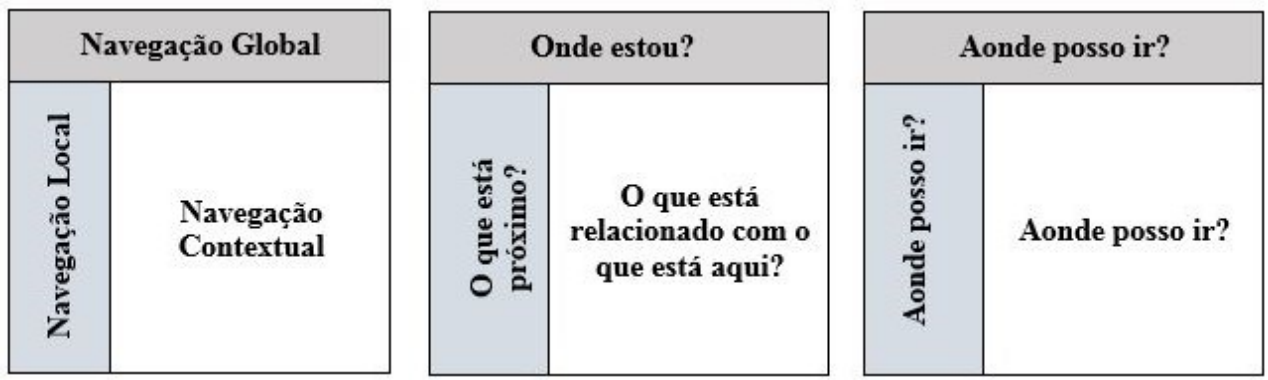

Fonte: Morville; Rosenfeld (2006, p. 116). 
O sistema de navegação suplementar (FIGURA 2) oferece alternativas de acesso ao conteúdo fora da área contextual ou da hierarquia estabelecida. As soluções apresentam ao usuário maneiras de navegar através de informações sumarizadas que propiciam a visualização dos dados de forma mais detalhada (REBELO, 2009).

Figura 2 - Sistema de navegação suplementar

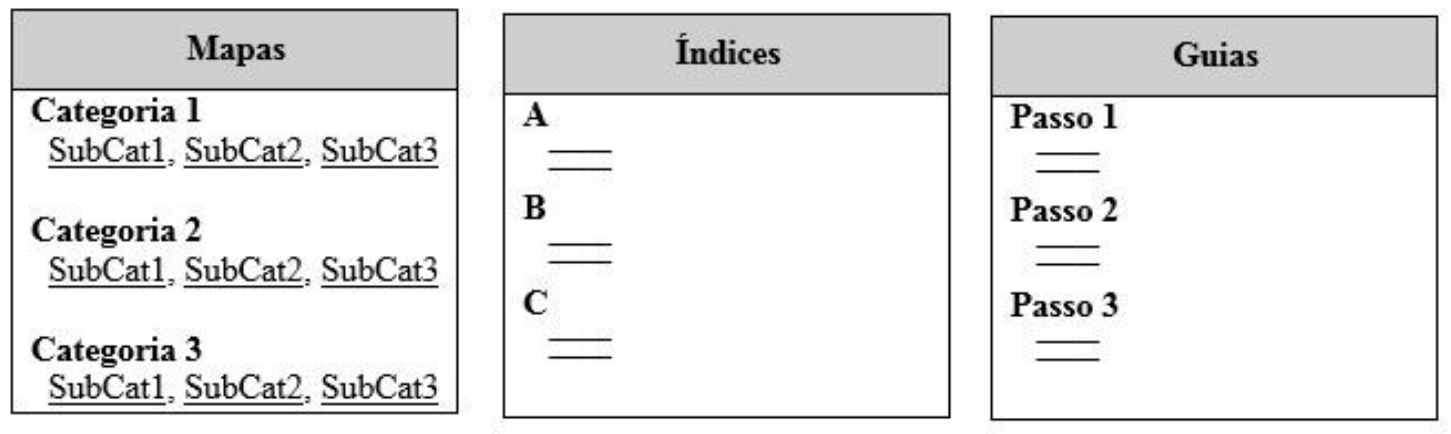

Fonte: Morville; Rosenfeld (2006, p. 116).

Em suma, o sistema de navegação especifica as maneiras de se mover pelo espaço informacional que foi agrupado e categorizado pelo sistema de organização. Assim, a concepção sem critérios em algum deles poderá refletir no mau funcionamento do outro.

\subsection{ASPECTOS REFERENTES À MODELAGEM}

Representar o conhecimento, de acordo com Brascher e Café (2008), não está restrito apenas ao Conhecimento exposto por um autor, na verdade, trata-se do resultado de um processo de análise de domínio que tem como objetivo pensar uma "visão consensual sobre a realidade que se pretende representar. A representação do conhecimento reflete um modelo de abstração do mundo real, construído para determinada finalidade" (BRASCHER; CAFÉ, 2008, p. 6).

O processo de modelização utiliza-se de sistematizações teóricometodológicas fundamentadas por princípios tais como método de raciocínio, o objeto de representação, as relações entre os objetos e as formas de representação (CAMPOS, 2004). 
A formulação de um mecanismo de representação do conhecimento apoiado na modelagem conceitual dispõe de uma estrutura composta por relacionamentos entre os seres ou objetos de um determinado contexto (PEREIRA, 2014).

Valendo-se dos argumentos de Cougo (1997, p. 3), percebe-se que "[...] quanto mais próximos estivermos de um modelo conceitual, mais afinidades e similaridades são encontradas no processo de modelagem de dados (modelo entidade-relacionamento) ou de informações (modelo de objetos) ".

Como descrito por Morville e Rosenfeld (2006), o modelo de conteúdo é um componente da Arquitetura da Informação que auxilia na definição dos objetos que deverão fazer parte do ambiente informacional. De acordo com os pesquisadores, trata-se de uma ferramenta útil para compreender o âmbito e a natureza do conteúdo.

No que se refere aos modelos de navegação, Kalbach (2009) apresenta o 'modelo-apenas-ligações-de-conteúdo', que diz respeito a uma coleção de páginas ligadas mutuamente sem que haja uma organização hierárquica ou parâmetros para que as ligações ocorram. Nesse caso, os links para navegação estão embutidos no texto disponível, não havendo um esquema de navegação e nem um ponto de partida advinda da página principal tradicional.

Já o modelo 'informação líquida' não apresenta links. A sua principal característica reside no fato de que cada uma das palavras possui algum tipo de interação, independente do texto apresentado. Dessa forma, não há diferença entre texto e hipertexto, ou entre conteúdo e navegação. Esse modelo permite que haja vários tipos de navegação a partir de uma determinada palavra (KALBACH, 2009).

No modelo de navegação estrutural, é disponibilizado um grupo de links; que podem estar posicionados ao lado de cada página. Tais links conduzem o usuário à informação pretendida, sendo que a área apresentada na tela pode ser alterada de acordo com os cliques efetuados. Há, ainda, uma hierarquia de páginas que podem ser percebidas visualmente. De acordo com a opção de navegação do usuário, é possível ir para níveis acimas ou abaixo da árvore. Dessa maneira, o conteúdo exposto é atualizado conforme a movimentação realizada (KALBACH, 2009).

Por fim, o autor apresenta o modelo de navegação web, que mescla um pouco de cada um dos modelos mencionados acima. Esse modelo usa como base a navegação estrutural, que é combinada com outras alternativas, tais como: as ligações de conteúdo e os mecanismos de busca e filtro. 


\section{METODOLOGIA}

No que se refere a natureza desta pesquisa, pode-se tipificá-la como uma Pesquisa Aplicada, pois visa "gerar conhecimentos para a aplicação prática dirigida a soluções de problemas específicos" (SILVA, 2004, p. 14). Tal tipo de pesquisa pode ser entendida como um modelo que adota "teorias ou leis mais amplas como ponto de partida, e tem como objetivo pesquisar, comprovar ou rejeitar hipóteses sugeridas por modelos teóricos e fazer a sua aplicação à diferentes necessidades humanas" (OLIVEIRA, 2001, p. 123).

Em relação ao tipo de abordagem do problema, esta pesquisa pode ser classificada como uma Pesquisa Qualitativa, uma vez que Reneker (1993) afirma que a pesquisa qualitativa é indutiva, ou seja, o pesquisador é o agente responsável pelo desenvolvimento de conceitos, ideias e compreensões a partir de padrões encontrados nos dados, não havendo a necessidade de coletar dados para comprovar teorias, hipóteses e modelos preconcebidos, ou seja, a pesquisa qualitativa "trabalha com o universo dos significados, dos motivos, das aspirações, das crenças, dos valores e das atitudes" (MINAYO, 2007, p. 21).

A respeito dos seus objetivos, esta pesquisa pode ser definida como uma Pesquisa Exploratória, já que "visa proporcionar maior familiaridade com o problema com vistas a torna-lo explícito ou construir hipóteses" (SILVA, 2004, p. 15).

Considerando os procedimentos técnicos de coleta e análise de dados, torna-se possível classificar este estudo sob três perspectivas:

1) Pesquisa Bibliográfica, pois o conteúdo abordado é assegurado pelo levantamento de fontes de informação baseado em livros, artigos, monografias, dissertações e teses provenientes das áreas de Biblioteconomia, Ciência da Informação e Tecnologia da Informação. Tais documentos foram obtidos a partir de consultas realizadas em bibliotecas físicas e eletrônicas, portais de pesquisa, repositórios institucionais e anais de eventos.

2) Pesquisa Documental, tendo em vista a necessidade de se efetuar o levantamento das tipologias documentais que possuíssem caráter científico. Em virtude disso, procedeu-se consulta aos documentos institucionais: Relatório de Gestão do ano de 2014, e caderno de "Normas para apresentação de trabalhos acadêmicos e 
científicos: documento impresso e/ou digital" publicado pelo Ifes. Foram também extraídas informações disponibilizadas no website da referida Instituição, assim como no software Pergamum, que faz o gerenciamento do acervo das Bibliotecas do Ifes.

3) Estudo de Caso, uma vez que se encarrega de explorar exaustivamente o Instituto Federal do Espírito Santo, avaliando a sua atuação dentro do contexto estudado. Para isso, é necessário obter conhecimento amplo e detalhado sobre as suas características. Assim, procedeu-se investigação sobre os fenômenos envolvidos na gestão e disseminação da produção científica da referida instituição.

Com a intenção de delinear uma abordagem pertinente à definição dos instrumentos adotados neste estudo, buscou-se identificar e analisar os processos, elementos, métodos e/ou técnicas advindas da Arquitetura da Informação, considerando seu amplo escopo metodológico e o referencial teórico escolhido.

\section{RESULTADOS FINAIS}

Composto por 21 campi, o Instituto Federal do Espírito Santo conta ainda com o Centro de Referência em Formação e em Educação a Distância (Cefor), que oferta diversos cursos em diferentes níveis na modalidade a distância.

A área de abrangência do Ifes compreende todo o território do Estado do Espírito Santo, com concentrações em microrregiões. Atendem, também, à demanda de vários municípios dos Estados que fazem limite com o Espírito Santo. A oferta de cursos é realizada conforme a vocação da região onde cada campus está inserido e de acordo com os arranjos produtivos locais ${ }^{1}$.

Os Cursos Técnicos são subdivididos de acordo com uma lógica diferente daquela das outras duas modalidades, pois são ofertados em cinco regimes distintos: concomitante, subsequente, integrado ao Ensino Médio, como Programa de Educação de Jovens e Adultos (Proeja) e como Ensino a Distância (EAD). No regime concomitante e no subsequente, o aluno faz somente o Ensino Técnico no Instituto, com a diferença de que, no regime concomitante, o discente ainda pode

\footnotetext{
${ }^{1}$ Arranjo Produtivo Local caracteriza-se por um aglomerado significativo de empreendimentos em determinado território e indivíduos que atuam em torno de uma atividade produtiva predominante, que compartilham formas percebidas de cooperação e algum mecanismo de governança, e pode incluir pequenas, médias e grandes empresas. (ESPÍRITO SANTO, 2011).
}

Rev. Inf. na Soc. Contemp., Natal, RN, Número Especial, 2017 | 
estar matriculado em uma determinada série do Ensino Médio, enquanto no subsequente a conclusão do Ensino Médio é obrigatória. No integrado, o aluno faz o Ensino Médio juntamente com a formação técnica no próprio instituto.

Baseando-se nas "Normas para apresentação de trabalhos acadêmicos e científicos: documento impresso e/ou digital"2, foi possível elencar os principais tipos de materiais informacionais que se espera que a comunidade acadêmica do Ifes produza. Em seguida, foram apuradas as tipologias documentais aptas a serem incorporadas no sistema de gerenciamento de bibliotecas ${ }^{3}$ do referido instituto. Por fim, consultou-se a literatura ${ }^{4}$ a fim de legitimar o que foi averiguado.

As Patentes foram consideradas convenientes para o ambiente estudado em razão das suas características, uma vez que os assuntos técnicos possuem informações relevantes para a comunidade acadêmica e sociedade em geral.

Assim, elaborou-se o Quadro 1, que arrola todos os documentos considerados apropriados para compor o RI do Ifes.

Quadro 1 - Tipos de documentos para serem inseridos no RI do Ifes

\begin{tabular}{|c|c|c|}
\hline \multicolumn{3}{|c|}{ Documentos } \\
\hline $\begin{array}{l}\text { Artigos de } \\
\text { periódicos }\end{array}$ & Livros & Trabalhos apresentados em Eventos \\
\hline Capítulos de livros & Patentes & $\begin{array}{c}\text { Trabalhos de Conclusão de Curso } \\
\text { de Graduação }\end{array}$ \\
\hline Dissertações & $\begin{array}{c}\text { Relatórios Técnicos e de } \\
\text { Pesquisa }\end{array}$ & $\begin{array}{c}\text { Trabalho de Conclusão de Curso de } \\
\text { Especialização }\end{array}$ \\
\hline Fascículos ${ }^{5}$ & Teses & \\
\hline
\end{tabular}

Fonte: elaborado pelo autor (2016).

Destaca-se também a Editora do Ifes, cujas atribuições vão desde a intermediação para solicitação de registro de ISBN até a publicação das obras ${ }^{6}$ que possuem relação com a instituição. Além disso, foi observada a existência de três revistas científicas pertencentes ao Instituto, a Revista Eletrônica Debates em Educação Científica e Tecnológica; a Revista Eletrônica Sala de Aula em Foco; e a Revista Ifes Ciência.

\footnotetext{
2 INSTITUTO FEDERAL DO ESPÍRITO SANTO (2014).

3 Pergamum.

${ }^{4}$ CAMPELLO; CENDÓN; KREMER (2000).

${ }^{5}$ Embora não tenham surgido em nossos levantamentos, entendemos que os Fascículos devem ser considerados pertinentes para o RI uma vez que se trata de uma publicação editada em cadernos que podem reunir artigos científicos de revistas.

${ }^{6}$ Impressas ou digitais.
} 
Definiu-se como relevante conhecer outras ações voltadas ao ensino, à pesquisa e à extensão, as quais pudessem resultar na publicação de documentos científicos tendo sido identificados alguns eventos realizados nos diversos campi do Ifes. A partir desse levantamento, averigou-se a possibilidade de documentos típicos, tais como os anais de eventos, serem originados em razão das atividades praticadas.

A fim de compreender como o conjunto desses elementos poderiam estar relacionados, elaborou-se o inventário de conteúdo, que serviu de subsídio para se gerar o modelo de conteúdo pretendido, pois complementou e convalidou os elementos apresentados.

A investigação realizada apontou para a necessidade do estabelecimento de alguns requisitos para que os usuários interajam com o repositório. Logo, a solução encontrada para satisfazer esse cenário foi a designação dos atores reais capazes de executar ações específicas, tendo sido necessário dividir os usuários em três grupos:

- Administradores: com a responsabilidade de configuração e personalização do sistema, definem permissões específicas para cada grupo de usuários. Podem decidir e controlar quem pode depositar e/ou acessar os itens do repositório. Os profissionais habilitados para essa categoria são os analistas e/ou técnicos de $\mathrm{TI}$ juntamente com os bibliotecários;

- Colaboradores: com a função de cadastramento dos itens. Enquadram-se nesse grupo os autores e os bibliotecários;

- Leitores: são capazes de acessar os itens armazenados, exceto aqueles objetos informacionais que possuem algum tipo de restrição atribuída pelos administradores. São alunos, docentes e técnicoadministrativos do Ifes, bem como pesquisadores/usuários provenientes de outras localidades ${ }^{7}$.

A modelagem do conteúdo se propõe a analisar os requisitos e as funcionalidades do sistema para detectar os grupos (tipos) de conteúdo e as relações existentes entre eles.

${ }^{7}$ Com audiência tanto local quanto global. Rev. Inf. na Soc. Contemp., Natal, RN, Número Especial, 2017 | 
Após ser efetuado um breve esclarecimento de como funciona o modelo, disponibilizou-se a sua representação, conforme pode observado na Figura 4. 
Figura 3 - Modelo de conteúdo do RI

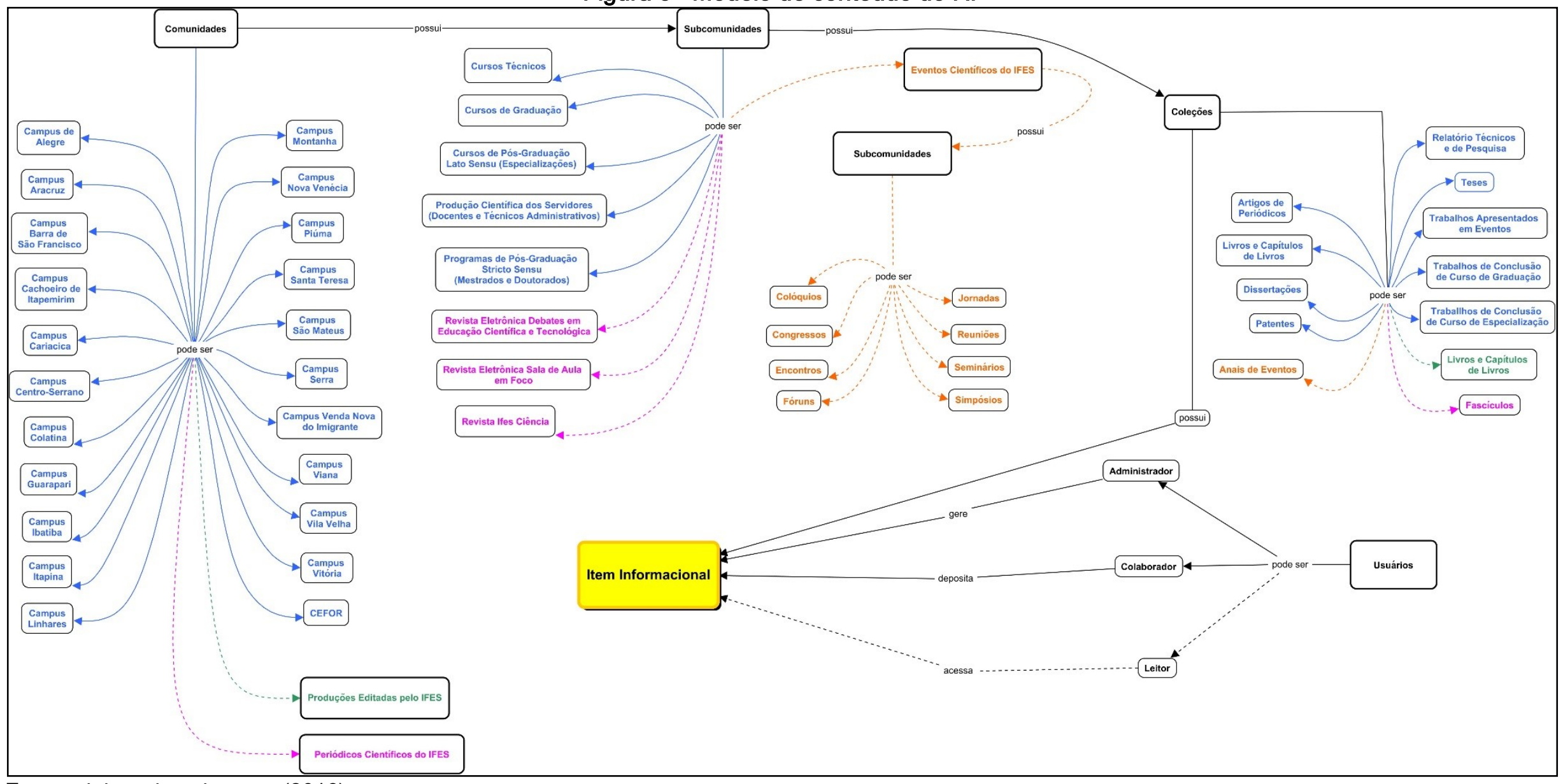

Fonte: elaborado pelo autor (2016). 
Percebe-se também que as principais comunidades estão divididas de acordo com as unidades dos campi existentes no Ifes, o que permite deduzir que esse segmento esteja inserido no esquema exato geográfico, uma vez que apresenta informações ordenadas segundo aspectos espaciais. É possível reconhecer que as comunidades, subcomunidades e coleções são organizadas alfabeticamente.

No que diz respeito aos esquemas ambíguos, há elementos que se enquadram na categoria orientado ao público, pois há subcomunidades divididas conforme o nível dos cursos oferecidos e de acordo com o que foi produzido pelos servidores da instituição .

Com relação à estrutura, o modelo é contemplado por uma organização hierárquica (top-down), ou seja, há uma ordem de classes e subclasses que partem das mais gerais para as mais específicas seguindo a ordem de importância.

De acordo com os requisitos, os leitores acessam o conteúdo autorizado pelo administrador, porém, o conteúdo visto pelos leitores é resultante do depósito realizado pelos colaboradores.

A partir da compreensão obtida, elaborou-se uma representação (FIGURA 4) que contemplasse os sistemas de organização e navegação. Sua função é representar as categorias dos conteúdos, funcionando como um mapa condensado para que os projetistas e utilizadores do site tenham uma visão geral unificada para o acesso aos conteúdos e serviços disponíveis. 
Figura 4 - Representação da navegação do repositório

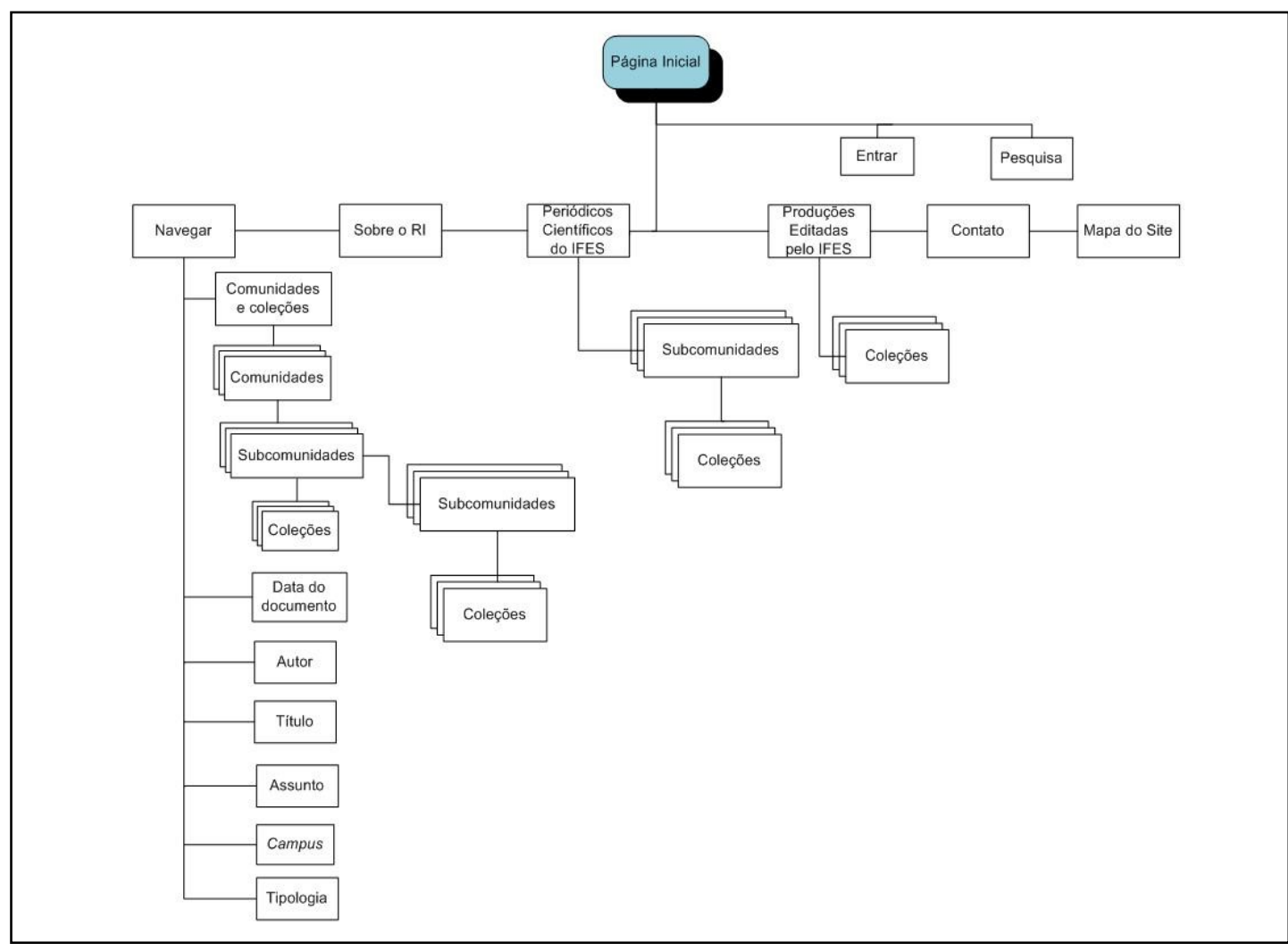

Fonte: elaborado pelo autor (2016).

A estrutura apresentada possui a característica top-down, o que permite aumentar o nível de detalhamento do produto final. Por mais exaustivo que fosse o levantamento dos documentos pertinentes para o ambiente informacional planejado, não haveria a garantia da inserção de todo o material produzido pelo instituto objeto deste estudo, tal como asseveram Costa e Leite (2009).

A representação da navegação que foi proposta apresenta os links e/ou caminhos que os usuários poderão executar enquanto estiverem acessando o sítio do repositório. Sua função é representar as categorias dos conteúdos, funcionando como um mapa condensado para que os projetistas e utilizadores do site tenham uma visão geral unificada para o acesso aos conteúdos e serviços disponíveis.

Para que fosse gerado o modelo de conteúdo, houve a necessidade de se elaborar um inventário que pudesse reunir os elementos necessários para o bom funcionamento do repositório em questão. 
O modelo que serviu de base para a confecção do inventário de conteúdo do RI encontra-se disponível na Figura 5.

Figura 5 - Modelo do inventário de conteúdo

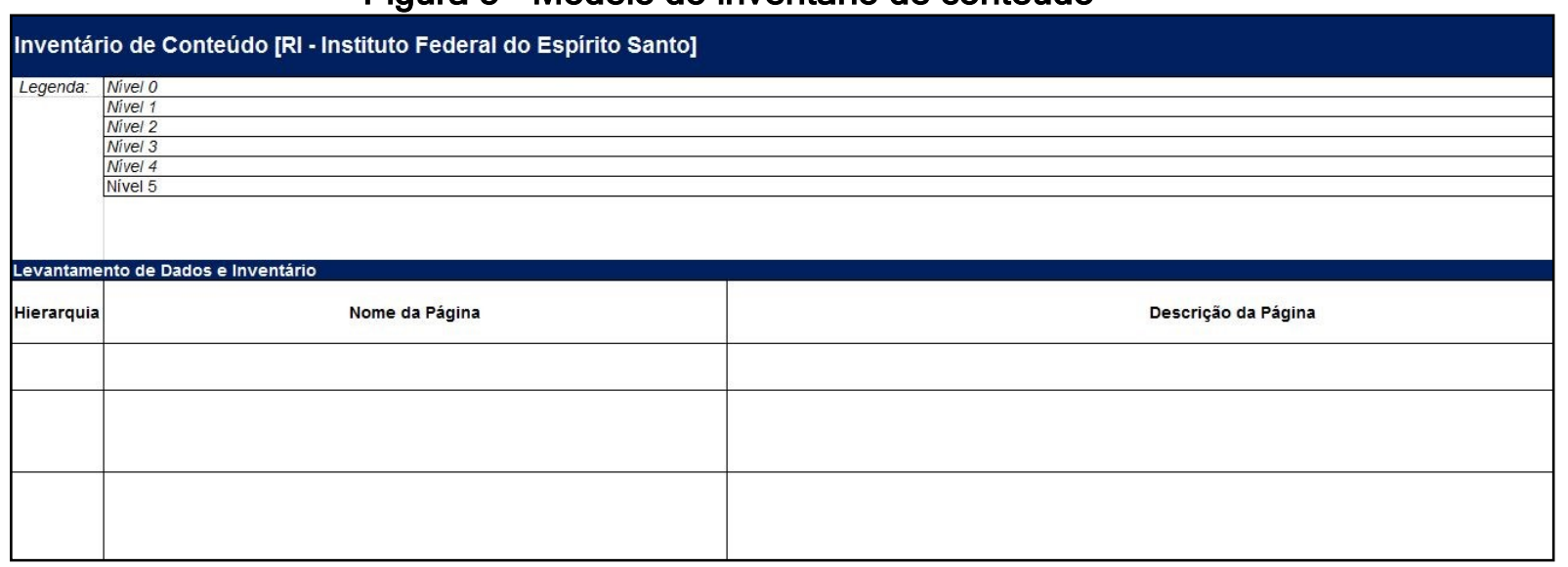

Fonte: elaborado pelo autor (2016).

\section{CONSIDERAÇÕES FINAIS}

Ao conduzir a pesquisa, identificou-se que o Instituto Federal do Espírito Santo não possui uma política institucional vigente que responsabilize e/ou delimite papéis para pessoas e/ou setores no que tange ao gerenciamento de documentos de natureza científica. Foi possível perceber ainda que a oferta de vários níveis e/ou modalidades de cursos impulsionou a criação de um imenso volume informacional de produção científica, fato que aponta para a necessidade de que seja estabelecido algum instrumento para o gerenciamento eficaz da produção científica em caráter de urgência, tal como um RI.

Para que esse estudo evoluísse, houve a necessidade da geração de um modelo de conteúdo que fosse concebido por meio da Al. Sendo assim, com o auxílio do inventário de conteúdo levantaram-se todas as informações relativas ao ambiente informacional em questão com a finalidade de subsidiar a construção do modelo supracitado.

A criação de modelos e/ou representações permite que tanto pessoas leigas quanto especialistas possam entender o ambiente planejado por diferentes perspectivas. O presente trabalho considera ainda que os profissionais da informação, tais como os bibliotecários, possuem conhecimento adequado para auxiliar na concepção de ferramentas online e serviços eletrônicos em vista de seus conhecimentos ligados à organização da informação. 
Ao fim, pode ser deduzido que, eventualmente, não será viável definir uma Al que possa ser ideal para todos os ambientes informacionais com características semelhantes. Em algumas ocasiões, as soluções não serão similares e a participação de outros profissionais poderá ser imprescindível. Sendo assim, acredita-se ser possível maximizar a compreensão sobre o mundo/domínio estudado a partir da Al.

Espera-se que este trabalho sirva de subsídio para que outros IFs possam avançar em relação à construção de seus Rls, tendo em vista a falta de pesquisas nas áreas de Biblioteconomia e Ciência da Informação voltadas para às IEPs com características similares aos atributos do Ifes.

\section{REFERÊNCIAS}

BARTON, M. R.; WATERS, M. M. Creating an institutional repository: LEADIRS workbook. [MIT Libraries] : S.I. 2004. Disponível em: <http://dspace.mit.edu/ bitstream/handle/1721.1/26698/Barton_2004_Creating.pdf?sequence=1>. Acesso em: 17 out. 2015.

BRASCHER; M.; CAFÉ, L. Organização da informação ou organização do conhecimento? In: ENCONTRO NACIONAL DE PESQUISA EM CIÊNCIA DA INFORMAÇÃO -ENANCIB, 9., 2008, São Paulo. Anais... São Paulo: ECA/USP, ENANCIB, 2008. Disponível em:< http://www.ancib.org.br/ media/ dissertacao/ 1835.pdf>. Acesso em: 18 maio 2015.

CAMPELLO, B. S.; CENDÓN, B. V.; KREMER, J. M. (Org.). Fontes de informação para pesquisadores e profissionais. Belo Horizonte: UFMG, 2000.

CAMPOS, M. L. A. Modelização de domínios de conhecimento: uma investigação de princípios fundamentais. Ciência da Informação. Brasília, v.33, n.1, p. 22-32, jan./abr. 2004. Disponível em:

<http://www.scielo.br/pdf/ci/v33n1/v33n1a03.pdf >. Acesso em 10 nov. 2014.

CARDELLO, J. The difference between information architecture (ia) and navigation. Nielsen Norman Group, [S.I.], 2014. Disponível em:

<http://www.nngroup.com/ articles/ia-vs-navigation/>. Acesso em: 26 jan. 2016. 
COSTA, S. M. de S.; LEITE, F. C. de. Insumos conceituais e práticos para iniciativas de repositórios institucionais de acesso aberto à informação científica em bibliotecas de pesquisa. In: SAYÃO, L. et. Al. (Org.). Implantação e gestão de repositórios institucionais: políticas, memória, livre acesso e preservação. Salvador: EDUFBA, 2009.

COSTA, S. M. S.; MOREIRA, A. C. The diversity of trends, experiences and approaches in electronic publishing: evidences of a paradigm shift on communication. In: ELPUB CONFERENCE ON ELECTRONIC PUBLISHING, 7., 2003, Portugal. Proceedings... Portugal: Universidade do Minho, 2003. Disponível em: <http://repositorio.unb.br/handle/10482/1024 >. Acesso em: 20 nov. 2015.

COUGO, P. Modelagem conceitual e projeto de bancos de dados. Rio de Janeiro: Elsevier, 1997.

CROW, R. The case of institutional repositories: a SPARC position paper. Washignton: SPARC, 2002. Disponível em: <http://www.sparc.arl.org/sites/ default/files/media_files/instrepo.pdf>. Acesso em 20 nov. 2013.

D'ANDRÉA, C. Estratégias de produção e organização de informações na web: conceitos para a análise de documentos na internet. Ciência da Informação, Brasília, v. 35, n. 3, p. 39-44, set./dez., 2006. Disponível em: <http://www.scielo.br/ pdf/ci/v35n3/v35n3a04>. Acesso em: 13 out. 2014.

ESPÍRITO SANTO (Estado). Secretaria de Desenvolvimento. Arranjos produtivos locais. Espírito Santo, 2011. Disponível em:

<http://www.sedes.es.gov.br/index.php/ arranjos-produtivos-locais/o-que-saoapls>. Acesso em: 17 set. 2014.

INSTITUTO BRASILEIRO DE INFORMAÇÃO EM CIÊNCIA E TECNOLOGIA. Manifesto brasileiro de apoio ao acesso livre à informação científica. Brasília, 2005. Disponível em: <http://livroaberto.ibict.br/docs/Manifesto.pdf>. Acesso em: 20 nov. 2013.

INSTITUTO FEDERAL DO ESPÍRITO SANTO. Normas para apresentação de trabalhos acadêmicos e científicos: documento impresso e/ou digital. 7. ed. Vitória: Ifes, 2014.

KALBACH, J. Design de navegação web: otimizando a experiência do usuário. Porto Alegre: Bookman, 2009.

LEITE, F. C. L. Como gerenciar e ampliar a visibilidade da informação científica brasileira: repositórios institucionais de acesso aberto. Brasília: IBICT, 2009.

LEITE, F. C. L. et al. Boas práticas para a construção de repositórios institucionais da produção científica. Brasília: IBICT, 2012.

MACHADO, M. M. Open archives: panorama dos repositórios. 2006. $101 \mathrm{f}$. Dissertação (Mestrado em Ciência da Informação) - Universidade Federal de Santa Catarina, Florianópolis, 2006. 
MARCONDES, C. H.; SAYÃO, L. F.. À guisa de introdução: repositórios institucionais e livre acesso. In: SAYÃO, L. et. al. (Org.). Implantação e gestão de repositórios institucionais: políticas, memória, livre acesso e preservação. Salvador: EDUFBA, 2009.

MINAYO, M. C. de S. (Org.). Pesquisa social: teoria, método e criatividade. 26. ed. Petrópolis: Vozes, 2007.

MONTEIRO, F. de S. Organização da informação em repositórios digitais institucionais com ênfase na descrição física e descrição temática. 2008. $199 \mathrm{f}$. Dissertação (Mestrado em Ciência da Informação) - Universidade de Brasília, Brasília. Disponível em: <http://repositorio.unb.br/handle/10482/1096>. Acesso em: 20 out. 2014.

MORVILLE, P.; ROSENFELD, L. Information architecture for the world wide web. 3nd ed. Sebastopol, CA: O'Reilly, 2006.

OLIVEIRA, S. L. Tratado de metodologia científica: projetos de pesquisas, TGI, TCC, monografias, dissertações e teses. São Paulo: Pioneira, 2001.

PEREIRA, D. V. Modelagem e representação semântica de dados governamentais abertos da Previdência Social brasileira. 2014. $168 \mathrm{f}$.

Dissertação (Mestrado em Ciência da Informação) - Universidade Federal Fluminense, Niterói.

PERGAMUM. Informações gerais. 2014. Disponível em:

<http://www.pergamum.pucpr.br/redepergamum/pergamum_informacoes_gerai s.php?ind=1>. Acesso em: 13 out. 2014.

REBELO, I. B. Apostila de IHC: interação entre homem e computador. Brasília : Centro Euroamericano UNIEURO, 2009. Disponível em:

<https://irlabr.wordpress.com/apostila-de-ihc/>. Acesso em: 12 jan. 2016.

RENEKER, M. H. A qualitative study of information seeking among members of na academic community: methodological issues and problems. Library Quarterly, v. 63, n. 4, p. 487-507, Oct. 1993. Disponível em: < http://www.jstor.org/stable/4308868>. Acesso em: 12 dez. 2015.

ROSA, F.; GOMES, M. J. Dos promotores aos utilizadores: estudos sobre o RepositóriUM. In: Repositórios institucionais: democratizando o acesso ao conhecimento. Salvador: UFBA, 2010.

SILVA, C. R. de O. Metodologia e organização do projeto de pesquisa: guia prático. Fortaleza: Centro Federal de Educação Tecnológica, 2004.

TORINO, L. P. Organização da produção científica em repositórios institucionais: um parâmetro para a UTFPR. 2010. 150 f. Dissertação (Mestrado em Gestão da Informação) - Universidade Estadual de Londrina, Londrina. Disponível em: <http://repositorio.utfpr.edu.br/jspui/handle/1/77>. Acesso em: 13 out. 2014. 